\title{
Comparative Study of Open Reduction Internal Fixation with Proximal Humerus Interlocking System and Closed Reduction and Pinning with $\mathrm{K}$-Wire in Proximal Humeral Fracture
}

Younes Akel, Mohammed El Nahas, Saddam Rabei Ali Shafei

Orthopaedic Surgery Department, Faculty of Medicine, Al Azhar University

* Corresponding author: Saddam Rabei Ali Shafei, E-mail: Shafei.saddam@gmail.com

\begin{abstract}
Background: Treatment of proximal humerus fractures may be conservative or operative. Each procedure has some limitations and complications. A major disadvantage of conservative treatment is failure to obtain early mobilization, which results in a high rate of shoulder stiffness and pain and malunion or nonunion is likely with certain fracture types. Objective: To compare functional outcomes and complications after open reduction and internal fixation of proximal humerus fractures (type 2 and 3 Neer classification) by proximal humeral internal locking osteosynthesis system (PHILOS) versus percutaneous fixation with K- wires.Patients and methods: Our study was conducted upon 20 Patients $(\mathrm{M}=7, \mathrm{~F}=13)$ in elderly group with two parts (10 patients) and three parts (10 patients) proximal humerus fractures according to Neer's classification patients was randomized to either (group 1) who were treated by open reduction and internal fixation with PHILOS plate and (group 2) who were treated with percutenous K- wire fixation. Results: The mean follow up UCLA score was 30 points (range from 26 to 34) points in (group 1) and 31 points (range from 27 to 35) points in (group 2), values varied depending upon the fracture type with worst in 3 parts fractures. Conclusion: we obtained satisfactory results in both groups with each procedure having its advantages and short comings. We found that fixation with percutaneous K-wires presented an efficient treatment option with the advantages of minimal invasions and soft tissue dissection and PHILO'S plate fixation provided stable fixation with minimal implants problems and enabled early range of motion exercise to achieve acceptable functional results.
\end{abstract}

Keywords: Proximal humeral, fracture, PHILOS plate, percutaneous K-wires.

\section{INTRODUCTION}

Fracture of the proximal humerus is a common and debilitating injury occurring mainly in elderly and accounts for $4-5 \%$ of all fractures. Typical age of fracture is between 65 and 75 years and about $51 \%$ of such fractures are displaced (1). The proximal humerus is uniquely adapted to allow wide range of motion of the shoulder. Mobility is gained at the expense of stability. In fracture of the proximal humerus, biomechanics of this joint is disturbed if fracture fragments are not properly reduced and fixed ${ }^{(2)}$.

Defining appropriate treatment protocols is complicated by poor reproducibility and reliability of the commonly used classification system devised by Neer. Neer's classification evaluates the proximal humerus in four parts as the anatomical head, the greater and lesser tuberosities and the surgical neck. Any translations more than 1 centimeter or angulations more than 45 degrees in any part of the humerus are defined as displacement.

The treatment of proximal humerus fractures has been a subject of intense discussion and controversy for the last century with supporters of both operative and non-operative methods. Several treatment modalities have been proposed depending upon the fracture pattern, patients' age, level of activity and bone stock, amount of displacement of the fragments and associated medical co-morbidities: conservative treatment, open reduction and internal fixation (ORIF), percutaneous fixation and joint replacement ${ }^{(3)}$.
Open reduction and internal fixation included extensive surgical exposure and risks of damage to the vascular supply of the fragments. Fixed angle locking plates enable fixation of many complex fractures. It has the advantages of anatomical reduction and early mobilization. It may however be associated with higher rates of infection, damage to arteries and nerves and avascular necrosis of humeral head ${ }^{(4)}$. A percutaneous method of fixation allows for minimal soft tissue dissection thereby protecting the blood supply to the fracture fragments which promotes rapid healing and minimizes the chances of avascular necrosis. This is even more important in the elderly population as it allows a rapid return of function and independence. Numerous reports described percutaneous techniques of fixation of the proximal humerus fractures. Percutaneous fixation is believed to be best suited for two-part and some three-part fractures ${ }^{(5)}$.

Closed reduction and percutaneous pinning may allow displaced fractures of the proximal humerus to be reduced and stabilized by Kirschner wires, alone or wires clamped into a locking device, has a low risk of neurovascular complications or interference with glenohumeral joint motion,. The latter prerogatives may be of considerable importance when treating patients in poor general condition ${ }^{(6)}$.

\section{AIM OF THE WORK}

The aim of the study is to compare the functional outcome of the proximal humerus fracture fixation using k-wires fixation versus locked plates. 


\section{PATIENTS AND METHODS \\ Type of study}

Prospective Study to compare outcome (radiological and functional) between Percutaneous Fixation and Locked Plates in Proximal Humerus Fractures in elderly patients. This study was done between December 2018 and June 2019.

\section{Place of study}

Al Azhar University Hospitals (Al Hussin and Sayed Galal Hospitals).

\section{Ethical approval and Written informed consent:}

An approval of the study was obtained from AlAzhar University academic and ethical committee.

Every patient signed an informed written consent for acceptance of the operation.

\section{Inclusion criteria}

- Age: elderly.

- Displaced proximal humerus fractures of less than 14 days duration.

- Two - three -parts proximal humerus fracture with or without shoulder dislocation.

- No previous surgical intervention.

- No coexisting neurological or muscular diseases affecting the function of the treated shoulder.

\section{Exclusion criteria:}

- Neglected proximal humerus fractures more than 3 weeks.

- Open fractures.

- Patients with severe comorbidities incompatible with anesthesia.

- Previous surgical intervention.

- Coexisting neurological or muscular diseases Methodology affecting the function of the treated shoulder.

Like all other operative procedures in orthopedics, management of fractures of proximal humerus has preoperative, intra-operative and postoperative stages.

\section{Pre-operative Stage}

This includes:

1. Clinical evaluation (history, general examination and local examination).

2. Radiological evaluation.

3. Preoperative preparation of the patient.

\section{Clinical Evaluation:}

- Patient research number.

- Each patient in this study was carefully assessed clinically by taking a detailed clinical history and performing a thorough examination.

\section{Clinical History:}

- The clinical history aimed to cover the following:

- The mechanism of trauma.

- Exclusion of any pre-existing history of shoulder injury or dislocation.
- Hand dominance.

- Occupation.

- Any previous surgery, especially involving the shoulder.

- Pre-assessment of the patient by anesthesiologist to identify fitness for surgery (general history taken about cardiac, chest, renal, and hepatic problems, and chronic medical illness as diabetes mellitus or hypertension).

\section{Clinical Examination:}

A comprehensive general examination of each patient was performed. After stabilizing the patient's general condition, local clinical examination was performed with particular emphasis on the following:

\section{Complete neurovascular examination of the involved upper extremity}

Assessment of peripheral arterial pulsation at the affected extremity was performed to detect any possible insult to the brachial artery. Whenever the patient's condition permitted, a complete neurological examination was performed to assess any brachial plexus injury with special attention to the axillary nerve for light touch and pinprick in its autogenously area over the deltoid.

\section{Motor examination:}

Motor testing is usually not possible at this stage secondary to pain. Inferior translation of the distal fragment may result from deltoid atony and is not a true gleohumeral dislocation, this usually resolves by 4 weeks after fracture, but if it persists, it may represent a true axillary nerve injury.

\section{Radiological Evaluation:}

A precise radiological evaluation is the corner stone for a proper management of fractures of the proximal humerus. The aim of preoperative radiological evaluation was to:

- Determine the fracture type.

- Understand the fracture pattern.

- Exclude associated fractures or dislocations.

- Bone quality:

Inter cortical distance method for bone quality and bone mineral density assessment. Two levels used to measure the cortical thickness of humeral diaphysis. Level 1: Most proximal aspect of humeral diaphysis is at level in which endosteal borders of medial and lateral cortex are parallel. Level 2: is $20 \mathrm{~mm}$ distal to level 1 .

- Bone stock of the fragments.

\section{Group 1: (locked plates) \\ Patient position}

The patient is placed beach-chair position with the affected shoulder resting outside the 
perimeter of the operating table and small sand bag under the shoulder.

\section{Approach}

The fracture was exposed through a deltopectoral approach in which skin incision from coracoid process to proximal humeral shaft (on the level of axilla) both landmarks can be easily palpated, which range from $12-14 \mathrm{~cm}$. Then, we expose deltopectoral groove with the cephalic vein that can be identified by; course of muscle fibers, cephalic vein itself and fat tissue surrounding the vein and then retracted medially or laterally and it should be preserved to reduce the surgical edema of the limb. Bluntly dissection between deltoid and pectoralis muscle to expose clavipectoral fascia then incision of clavipectoral fascia and fracture fragments were reduced. The reduced fracture fragments were held in position with $\mathrm{K}$-wires under guidance of image intensifier. Most plates have a slotted gliding hole; this should be drilled first in its center to allow for minor adjustments in plate height. Definitive fixation with locked plate was done with the plate positioned lateral to the bicipital groove, sparing the tendon of long head of biceps. The plate was placed at least one $\mathrm{cm}$ distal to the upper end of greater tubercle. Range of motion of shoulder and impingement were checked on the table.

\section{Group 2: (K-wires fixation)}

After the arm and shoulder are draped freely, only longitudinal traction force is applied to the upper extremity with the shoulder in adduction to enable fracture reduction. Direct pressure or manipulation over the fracture site is avoided. Special care is taken concerning posterior sagging of the humerus shaft caused by gravity. Confirmation of realignment is undertaken with adjustment of the Carm of the image intensifier instead of rotation of the humerus. Kirschner wires are then used as joysticks for adjustment of the reduction. We typically use (4) 2.5-mm nonthreaded-tipped Kirschner wires (also known as pins). We describe the first wire as the reduction pin and the second wire as the antirotation pin and the third and fourth as the stabilization pins.

\section{Data Analysis}

Data were analyzed using IBM $\odot$ SPSS $\odot$ Statistics version 23 (IBM@ Corp., Armonk, NY, USA). Continuous numerical variables were presented as mean \pm SD (range) and categorical variables as number or proportion and percentage. Correlations among numerical variables were tested using the Pearson product-moment correlation.

RESULTS

Table (1): Differences in operative data according to study groups

\begin{tabular}{|c|c|c|c|c|c|c|}
\hline \multirow{2}{*}{\multicolumn{2}{|c|}{ Variable }} & $\begin{array}{c}\text { locked plate and } \\
\text { screws }\end{array}$ & $\begin{array}{c}\text { Percutaneous } \\
\text { pinning }\end{array}$ & \multirow{3}{*}{$\begin{array}{c}\begin{array}{c}\text { Test } \\
\text { value }\end{array} \\
1.290 \bullet\end{array}$} & \multirow{3}{*}{\begin{tabular}{|c|}
$\begin{array}{c}P- \\
\text { value }\end{array}$ \\
0.213
\end{tabular}} & \multirow{3}{*}{\begin{tabular}{|l|} 
Sig. \\
NS
\end{tabular}} \\
\hline & & No. $=10$ & No. $=10$ & & & \\
\hline $\begin{array}{c}\text { Interval between trauma } \& \\
\text { intervention in days }\end{array}$ & $\begin{array}{c}\text { Mean } \pm \text { SD } \\
\text { Range }\end{array}$ & $\begin{aligned} 2.80 & \pm 1.23 \\
1 & -4\end{aligned}$ & $\begin{aligned} 2.10 & \pm 1.20 \\
1 & -5\end{aligned}$ & & & \\
\hline Amount of blood loss in $\mathrm{cm}$ & $\begin{array}{c}\text { Median (IQR) } \\
\text { Range }\end{array}$ & $\begin{array}{c}325(250-400) \\
250-600\end{array}$ & $\begin{array}{c}3.50(3-5) \\
2-7\end{array}$ & $-3.800 \neq$ & 0.000 & HS \\
\hline Time of surgery in hours & $\begin{array}{l}\text { Mean } \pm \text { SD } \\
\text { Range }\end{array}$ & $\begin{array}{c}1.72 \pm 0.30 \\
1.3-2\end{array}$ & $\begin{array}{l}1.09 \pm 0.46 \\
0.45-2\end{array}$ & $3.614 \bullet$ & 0.002 & HS \\
\hline Time of IOP image in minute & $\begin{array}{c}\text { Mean } \pm \text { SD } \\
\text { Range }\end{array}$ & $\begin{array}{c}1.30 \pm 0.54 \\
0.5-2\end{array}$ & $\begin{array}{l}4.70 \pm 1.42 \\
2-6\end{array}$ & $-7.089 \bullet$ & 0.000 & HS \\
\hline Neer's classification & $\begin{array}{l}\text { Two part fracture } \\
\text { Three part fracture }\end{array}$ & $\begin{array}{l}4(40.0 \%) \\
6(60.0 \%)\end{array}$ & $\begin{array}{l}6(60.0 \%) \\
4(40.0 \%)\end{array}$ & $0.800 *$ & 0.371 & NS \\
\hline Length of skin incision & 14.2 & 2.23 & Less than $2 \mathrm{~cm}$ & $*$ & 0.00 & HS \\
\hline
\end{tabular}

In group (1) time of surgery is greater than that of group (2) which ranged from 1.5 to 2 hours in group (1) while in group (2) range from 30 minutes to 1.5 hours.

Table (2): Differences in active forward flexion according to study groups

\begin{tabular}{|c|c|c|c|c|c|c|}
\hline \multirow{2}{*}{\multicolumn{2}{|c|}{ Active forward flex in }} & locked plate and screws & Percutaneous pinning & \multirow{2}{*}{\begin{tabular}{|c} 
Test \\
value•
\end{tabular}} & \multirow{2}{*}{$\begin{array}{c}\mathbf{P}- \\
\text { value }\end{array}$} & \multirow{2}{*}{ Sig. } \\
\hline & & No. $=10$ & No. $=10$ & & & \\
\hline $3 \mathbf{m}$ & $\begin{array}{c}\text { Mean } \pm \text { SD } \\
\text { Range }\end{array}$ & $\begin{array}{c}79.50 \pm 20.47 \\
45-100\end{array}$ & $\begin{array}{c}73.00 \pm 19.89 \\
45-100\end{array}$ & $\mathbf{0 . 7 2 0}$ & 0.481 & NS \\
\hline $6 \mathrm{~m}$ & $\begin{array}{c}\text { Mean } \pm \text { SD } \\
\text { Range }\end{array}$ & $\begin{array}{c}124.50 \pm 41.53 \\
60-160\end{array}$ & $\begin{array}{c}117.00 \pm 42.11 \\
45-160\end{array}$ & 0.401 & 0.693 & $\mathbf{N S}$ \\
\hline \multicolumn{2}{|c|}{ Paired t-test } & -5.049 & -5.202 & & & \\
\hline \multicolumn{2}{|c|}{ P-value } & 0.001 (HS) & 0.001 (HS) & & & \\
\hline
\end{tabular}


Table (3): Relation between patient satisfaction and study groups

\begin{tabular}{|c|c|c|c|c|c|c|c|c|}
\hline \multirow{2}{*}{\multicolumn{2}{|c|}{ Patient satisfaction }} & \multicolumn{2}{|c|}{ Locked plate and screws } & \multicolumn{2}{|c|}{ Percutaneous pinning } & \multirow{2}{*}{$\begin{array}{c}\text { Test } \\
\text { value* }^{*}\end{array}$} & \multirow{2}{*}{$\begin{array}{c}\mathrm{P}- \\
\text { value }\end{array}$} & \multirow{2}{*}{ Sig. } \\
\hline & & No. & $\%$ & No. & $\%$ & & & \\
\hline $3 \mathbf{m}$ & $\begin{array}{c}\text { Non } \\
\text { Satisfied }\end{array}$ & $\begin{array}{l}5 \\
5\end{array}$ & $\begin{array}{l}\mathbf{5 0 . 0 \%} \\
\mathbf{5 0 . 0 \%}\end{array}$ & $\begin{array}{l}4 \\
6\end{array}$ & $\begin{array}{l}40.0 \% \\
60.0 \% \\
\end{array}$ & 0.202 & 0.653 & NS \\
\hline $6 \mathrm{~m}$ & $\begin{array}{c}\text { Non } \\
\text { Satisfied } \\
\end{array}$ & $\begin{array}{l}3 \\
7 \\
\end{array}$ & $\begin{array}{l}30.0 \% \\
70.0 \% \\
\end{array}$ & $\begin{array}{l}2 \\
8 \\
\end{array}$ & $\begin{array}{l}20.0 \% \\
80.0 \% \\
\end{array}$ & 0.267 & 0.606 & NS \\
\hline \multicolumn{2}{|c|}{ Chi-square test } & \multicolumn{2}{|c|}{$\mathbf{0 . 8 3 3}$} & \multicolumn{2}{|c|}{0.952} & & & \\
\hline \multicolumn{2}{|c|}{$\overline{P \text {-value }}$} & \multicolumn{2}{|c|}{0.361 (NS) } & \multicolumn{2}{|c|}{0.329 (NS) } & & & \\
\hline
\end{tabular}

There were 7 patients satisfied in group (1) and 8 patients satisfied in group (2).

Table (1): Relation between UCLA score and study groups

\begin{tabular}{|c|c|c|c|c|c|c|c|c|}
\hline \multirow{2}{*}{\multicolumn{2}{|c|}{ Result }} & \multicolumn{2}{|c|}{ locked plate and screws } & \multicolumn{2}{|c|}{ Percutaneous pinning } & \multirow{2}{*}{$\begin{array}{c}\text { Test } \\
\text { value* }\end{array}$} & \multirow{2}{*}{$\begin{array}{c}P- \\
\text { value }\end{array}$} & \multirow{2}{*}{ Sig. } \\
\hline & & No. & $\%$ & No. & $\%$ & & & \\
\hline \multirow{3}{*}{$3 m$} & Excellent & 3 & $30.0 \%$ & 2 & $20.0 \%$ & \multirow{3}{*}{0.978} & \multirow{3}{*}{0.613} & \multirow{3}{*}{ NS } \\
\hline & Good & 2 & $20.0 \%$ & 4 & $40.0 \%$ & & & \\
\hline & Poor & 5 & $50.0 \%$ & 4 & $40.0 \%$ & & & \\
\hline \multirow{3}{*}{$6 \mathrm{~m}$} & Excellent & 6 & $60.0 \%$ & 5 & $50.0 \%$ & \multirow{3}{*}{1.291} & \multirow{3}{*}{0.524} & \multirow{3}{*}{ NS } \\
\hline & Good & $\mathbf{1}$ & $10.0 \%$ & 3 & $30.0 \%$ & & & \\
\hline & Poor & 3 & $30.0 \%$ & 2 & $20.0 \%$ & & & \\
\hline \multicolumn{2}{|c|}{ Chi-square test } & \multicolumn{2}{|c|}{1.833} & \multicolumn{2}{|c|}{2.095} & & & \\
\hline \multicolumn{2}{|c|}{ P-value } & \multicolumn{2}{|c|}{0.400 (NS) } & \multicolumn{2}{|c|}{$0.351(\mathrm{NS})$} & & & \\
\hline
\end{tabular}

Post-operative follow up results according to UCLA scoring system, after 3 and 6 months shows no significant difference.

Table (2): Characteristics of study groups as regards complications

\begin{tabular}{|c|c|c|c|}
\hline \multirow[t]{2}{*}{ Variable } & $\begin{array}{c}\text { Group 1 } \\
(\mathrm{N}=\mathbf{2 0})\end{array}$ & $\begin{array}{c}\text { Group } 2 \\
(\mathrm{~N}=20)\end{array}$ & \multirow[t]{2}{*}{ P-value } \\
\hline & \multicolumn{2}{|c|}{$\mathbf{N}(\%)$} & \\
\hline \multicolumn{4}{|c|}{ Complications } \\
\hline Present & $4(40.0)$ & $3(30.0)$ & \multirow{2}{*}{1.000} \\
\hline Absent & $6(60.0)$ & $7(70.0)$ & \\
\hline \multicolumn{4}{|c|}{ Type of complications } \\
\hline Decrease ROM & $1(20.0)$ & $1(10.0)$ & \multirow{3}{*}{------ } \\
\hline Delayed union & $2(00.0)$ & $1(10.0)$ & \\
\hline Infection & $1(10.0)$ & $1(10.0)$ & \\
\hline
\end{tabular}

Both groups received broad spectrum antibiotics postoperatively. There was no major complications intraoperatively in both groups. Postoperative complications were noted in 4 patients in group (1) and 3 patients in group (2) with no significant difference between both groups.

\section{DISCUSSION}

Majority of the patients with proximal humerus fractures are above 60 years old and most of these fracture in these populations are due to osteoporosis. Conservative treatment in a sling followed by functional rehabilitation under the supervision leads to satisfactory results in minimally displaced fractures whereas, displaced two and three part fractures need to be reduced and stabilized.

Closed reduction and percutaneous pinning techniques are of paramount importance when treating the elderly patients with cardio-vascular or pulmonary diseases, in whom anesthesia is very risky or clearly contra-indicated. Open reduction and internal fixation in this population has some complications like increased morbidities due to anesthesia, more soft tissue damage, risk of a vascular necrosis of humeral head (AVN) causing functional impairment.

In this study, we examined a group of elderly patients (20 patients) with displaced fracture of proximal humerus (2 and 3 parts) according to Neer's classification. Patients were randomized to either (group 1) that was treated by open reduction and internal fixation with proximal humeral internal locking system (PHILOS) plate and (group 2) that was treated with percutenous $\mathrm{K}$ - wire fixation. We analyzed our results and followed up patients at 1, 3 then 6 months according to UCLA score. Seyhan $\boldsymbol{e t}$ 
al. (10) treated Thirty-six consecutive patients with proximal humerus fractures of two and three types with $\mathrm{K}$ wires, patients were followed up for an average of 38 months according to constant scoring system. Jura et $\boldsymbol{a l}$. ${ }^{(7)}$ performed their study on 60 patients with proximal humerus fractures with mean age was 64 years in 30 patients (Group 1), who were treated by open reduction and internal fixation with Proximal Humeral Internal Locking System (PHILOS) plate and 30 patients (Group 2) who were treated with percutaneous K-wire fixation. Follow up at 1 week then every month for 6 months according to Visual Analoge Score (VAS) and Constant-Murley score study was performed in two and three type fracture $^{(7)}$.

In our study, in group 1 mean operative time was 90 minutes (range from 70 to $110 \mathrm{~min}$.) and average blood loss was $500 \mathrm{ml}$. (range from 300 to $700 \mathrm{ml}$.). In group 2 mean operative time was 40 minutes (range from 30 to $50 \mathrm{~min}$.) and blood loss was less than $5 \mathrm{cc}$. Intra-operative imaging timing in group 1 ranged from 1 to 2 minutes while in group 2 ranged from 4 to 6 minutes. Both groups received broad spectrum antibiotics postoperatively. Jura et al. (7) stated that mean operation time was 100 minutes (range 80-120 minutes) in group 1 and 50 minutes (range 35-70 minutes) in group 2. In group 1 the average blood loss during surgery was $600 \mathrm{ml}$ (range $400-1000 \mathrm{ml}$ ), whereas in group 2 it was $100 \mathrm{ml}$ (range $70-160 \mathrm{ml}$ ). Both groups received broad spectrum antibiotics postoperatively.

In our study, more than $85 \%$ of the patients had excellent and good outcomes according to UCLA score system in group 1 . We were able to obtain reduction in all cases by this technique. In group 2, more than $80 \%$ had also good and excellent result according to UCLA score with measurement of active forward flexion, patient satisfaction and pain. Baldev and Sumit ${ }^{(17)}$ studied functional outcome of patients managed with $\mathrm{k}$-wire fixation. The study group consisted of twenty patients with two and three part fractures. The minimum follow up of the patients was 12 months. All the three part and the two part fractures were managed with k-wire fixation. Out of all patients, four patients had pin site infection, four patients had mal-union, one patient had non-union and no patients had avascular necrosis of the humeral head. From his study the average constant score was $73.65 \%$ out of these $10 \%$ had excellent functional outcome, $55 \%$ had good functional outcome, $20 \%$ had moderate and $15 \%$ had poor results (17). Aavolainen et al. ${ }^{(18)}$ in their study on open reduction and internal fixation of the proximal humerus fractures with the locking plate had higher complication rate with $7.9 \%$ avascular necrosis, 11.7 $\%$ screw cut out and $13.7 \%$ needed revision surgery. These complications of the locking plate can be prevented by good surgical technique
In our study, There were no major complications intraoperative in both groups. Postoperative complications were noted in 4 patients in group (1) and 3 patients in group (2). In group (1) one patient had superficial wound infection this patient was diabetic, 62 years old and he was treated by intravenous antibiotics after obtaining culture and sensitivity reports and repeated dressings. Also, one case of delayed union after 5 months (patient with three parts fracture). Another patient had implant failure and non-union, which was treated by removal of plate and bone graft. The last had decreased range of motion after 3 and 6 months. In group (2), one patient had pin tract infection (patient with three parts fracture) and he was treated by daily dressings and antibiotics. Another one had delayed union after 5 months and the last had decreased range of motion after 3 and 6 months. Seyhan et al. ${ }^{(10)}$ reported that there was pin tract infection in 2 cases and resolved with oral antibiotics after the pin removal. Jura et al. (7) reported that in group 1, two patients had nonunion, four patients had infection and two patients had avascular necrosis of the head of the humerus. In group 2, six patients had pin tract infection, two patients had non-union (both of them had 3 part fracture), four patients had malunion (three patients with 2 part fracture and one patient with 3 part fracture) and two patients had K-wire loosening (both of them had 2 part fracture). Bogner et al. ${ }^{(11)}$ reported in their study on 48 patients with two and three part fracture fixed by $\mathrm{K}$ - wires, that implant failure and loss of reduction due to K-wires migration was observed in $10 \%$, while AVN in $7.8 \%$. These patients were older than 60 years.

The most common technical error was placement of pins too close together so that only a portion of the head fragment was fixed. Another technical error was insertion of a Kirschner pin at a point so near to the fracture site as to result in further fragmentation of metaphysis. There were no cases of deep infection, nonunion, avascular necrosis, or implant failure.

In our study, the first phase of physiotherapy rehabilitation in group (1) was in the form of pendulum exercises that started on the first postoperative day and was continued till suture removal. Active-assisted exercises of the shoulder started at third week and continued for 6 weeks. In the 4th week, active mobilization without weight was performed and, finally, in the 6th week full active mobilization began. The second phase of physiotherapy, started approximately 6 weeks after surgery by mobilization and weight bearing but it must be pain limited. The third phase, the exercises generally began after 3 months and characterized by a program of progressive strengthening and maintenance. In group (2), postoperative care included arm immobilization in a sling for 3 to 4 weeks. Passive and pendulum exercises are initiated as soon 
as pain and swelling subsided. Clinical and radiographic evaluations are performed at 1,3 , and 6 weeks. The reduction and antirotation pins are removed at 4 weeks. The stabilizing pins are removed at 6 weeks when there was radiographic evidence of union. More aggressive motion and rotation exercises are then instituted to regain the range of motion of the shoulder at 2 months after surgery. Jura et al. ${ }^{(7)}$ started passive range of motion (ROM) exercises on the second postoperative day in both groups then active shoulder mobilization exercises were started 4 to 6 weeks postoperatively depending on the patient's co-operation.

Seyhan et al. (10) believed that closed reduction using the joystick method of K-wires reduction and percutaneous fixation provided reasonable treatment, despite being technically demanding satisfactory realignment and sufficient fixation that can be accomplished with meticulous radiographic assessment. Magovern and Kenner ${ }^{(15)}$, and Nho et al. ${ }^{(13)}$ found good constant scores with surgery and relatively few complications, with better functional scores for percutaneous fixation. Percutaneous fixation has its limitations of poor reduction of fracture fragments, pin tract infection and long period of recovery ${ }^{(15,14)}$. However, it has the advantages of less soft tissue stripping with less exposure, less blood loss and minimal invasiveness. In cases where there is loss of reduction due to pin loosening, ORIF can be performed. ORIF with PHILOS plate for treatment of proximal humerus fractures has the advantages of accurate reduction, early mobilization, better fixation in osteoporotic bones and ease of reconstruction of comminuted irreducible fractures. On the other hand, it has the disadvantages of excessive soft tissue dissection and blood loss, risks of injury to the neurovascular structures and increased risk of avascular necrosis of humeral head. However, recent studies have shown good long term results of proximal humerus fractures managed by the PHILOS plate ${ }^{(16)}$.

Shiva et al. ${ }^{(12)}$ in their study also observed that the functional outcome of the patients who underwent K-wire fixation below the age of 60 years (5 patients) was $81.6 \%$ and more than 60 years old of age (6 patients) was $66.8 \%$. Similarly, functional outcome of plating below 60 years (10 patients) of age was $85.3 \%$ and more than 60 years (5patients) of age was $72 \%$.

\section{CONCLUSION}

We obtained satisfactory results in both groups, with each procedure having its advantages and drawbacks. We found that fixation with percutaneous $\mathrm{K}$-wires presented an efficient treatment option with the advantages of minimal invasiveness of soft tissue and less blood loss. PHILOS plate fixation provided stable fixation with minimal implant problems and enabled early range of motion exercises to achieve acceptable functional results.

Percutaneous pinning is more important in elderly population as it allow rapid return to function except in sever osteoporosis or significant comminution. Use of $\mathrm{K}$-wire with threaded tip can prevent migration. However it is difficult to be removed easily after fracture union. The most common technical error was placement of pins too close together so that only a portion of the head fragment was fixed. Another technical error was insertion of a K-wire at a point so near to the fracture site result in further fragmentation of metaphysis. Reduction can't be achieved in closed manner and so open reduction was done in 2 cases. Closed reduction in three parts fracture may be difficult as greater tuberosity displacement can't be easily reduced anatomically so some cases with three parts fracture with greater tuberosity displacement need open reduction with $\mathrm{K}$-wires or even screw fixation.

\section{REFERENCES}

1. Konrad G, Bayer J, Hepp P (2010): Open Reduction and Internal Fixation of Proximal Humeral Fractures with Use of the Locking Proximal Humerus Plate. J Bone Joint Surg Am., 92: 85-95.

2. David J, Harold E, Patricia C (2005): Gray's Anatomy, 39th edition, Pectoral Girdle and Upper Limb. Published by Elsevier Churchill Livingstone, Pp: 908-940.

3. Jon JP, John GC, Christian G (2006): Fracture of Proximal Humerus. In: Bucholz, Robert W, Heckman, James D, Court-Brown, Charles M.(eds). Rockwood \& Green's Fractures in Adults, 6th Edition. https://www.worldcat.org/title/rockwood-and-greensfractures-in-adults/oclc/300348277

4. Crenshaw AH, Perez EA (2007): Fractures of the Shoulder, Arm, and Forearm. Canale \& Beaty: Campbell's Operative Orthopedics, $11^{\text {th }}$ ed, published by Mosby, Pp: 2985-3070.

5. Burkart AC, Debski RE (2002): Anatomy and function of the glenohumeral ligaments in anterior shoulder instability. Clin Orthopaed Related Res., 400: 369-379.

6. Michener LA, McClure PW, Karduna AR (2003): Anatomical and biomechanical mechanisms of subacromial impingement syndrome. Clin Biomech., 18: 369-79.

7. Tingart MJ, Apreleva M, Von SD et al. (2003): The cortical thickness of the proximal humeral diaphysis predicts bone mineral density of the proximal humerus. Journal of Bone and Joint Surgery-British, 85 (4): 611617.

8. Neer CS, Rockwood CA (1984): Fractures and dislocations of the shoulder. In: Rockwood CA, Green DP, eds. Fractures in adults, $2^{\text {nd }}$ ed. Philadelphia: JB Lippincott, Pp: 675-721.

9. Waleed M E, Mahmoud A E (2014): Functional outcome of locked-plate fixation of displaced threepart and four-part fractures of the proximal humerus. Egyptian Orthopedic Journal, 49: 309-313.

10. Seyhan M, Kocaoglu B, Nalbantoglu U et al. (2012): Technique of Kirschner wire reduction and fixation of 
displaced two-part valgus angulated proximal humerus fractures at the surgical neck. Journal of Orthopaedic Trauma, 26: 46-50.

11. Bogner $\mathrm{R}$, Hübner $\mathrm{C}$, Matis $\mathrm{N}$ et al. (2008): Minimally-invasive treatment of three-and four-part fractures of the proximal humerus in elderly patients. The Journal of Bone and Joint Surgery. British, 90 (12): 1602-1607.

12. Shiva S, Shyam S, Dinkar R (2015): Functional outcome of two part and three part proximal humerus fractures - A comparative study between K-wire and plate fixation. IOSR J Dent Med Sci., 14: 48-58.

13. Nho SJ, Brophy RH, Baker JU et al. (2007): Management of proximal humerus fractures based on current literature. J Bone Joint Surg [Am], 89: 44-58.

14. Kenner JD, Parsons BO, Flatow EL et al. (2007): Outcomes after percutaneous reduction and fixation of proximal humerus fractures. J Shoulder Elbow Surg., 16: $330-338$

15. Magovern B, Ramsay ML (2008): Percutaneous fixation of proximal humerus fractures. Orthop Clin North Am., 39: 405-416

16. Olerud P, Ahrangart L, Ponzer S et al. (2011): Internal fixation versus non operative treatment of displaced 3 part proximal humerus fractures in elderly patients: A randomised controlled trial. J Shoulder Elbow Surg., 20: 747-755.

17. Baldev D, Sumit D (2011):Functional outcome of treatment of proximal humerus fractures with close reduction and k-wire fixation. Journal of Maharashtra Orthopaedic Association, 11 (7): 10-13.

18. Aavolainen $\mathbf{P}$, Björkenheim JM, Slätis $P$ et al. (1983): Operative treatment of severe proximal humeral fractures. Acta Orthop Scand., 54: 374-9. 